\title{
ESTADO E GOVERNO: DIFERENÇA CONCEITUAL E IMPLICAÇÕES PRÁTICAS NA PÓS-MODERNIDADE
}

\section{Resumo:}

É comum e indevido confundir oEstado com o governo. OEstado é toda a sociedade política, incluindo o governo. Ogoverno é principalmente identificado pelo grupo político que está no comando de um Estado. OEstado possui as funções executiva, legislativae judiciária. O governo, dentro da função executiva, se ocupa em gerir os interesses sociais e econômicos da sociedade, e de acordo com sua orientação ideológica, estabelece níveis maiores ou menores de intervenção. Assim, governo também não se confunde com o poder executivo, esteé composto pelo governo, responsável pela direção política do Estado, e pela administração, como conjunto técnico e burocrático que auxilia o governo e faz funcionar a máquina pública. A administração pública dá execução às decisões do governo. Na pós-modernidade as funções do Estado continuam as mesmas, atémesmo o pragmatismo de sua separaçãoé aceito, entretanto no limite de sua eficiência, e não na necessidade de garantir um Estado Democrático e de Direito.

Palavras-chave: Estado, Governo, Pós-Modernidade.

\section{Introdução}

É comum e indevido confundir o Estado com o governo. O Estado é toda a sociedade política, incluindo o governo. O governo é principalmente identificado pelo grupo político que está no comando de um Estado. O Estado possui as funções executiva, legislativa e judiciária. O governo, dentro da função executiva, se ocupa em gerir os interesses sociais e econômicos da sociedade, e de acordo com sua orientação ideológica, estabelece níveis maiores ou menores de intervenção. Assim, governo também não se confunde com o poder executivo, este é composto pelo governo, responsável pela direção política do Estado, e pela administração, como conjunto técnico e burocrático que auxilia o governo e faz funcionar a máquina pública.

*Mestre em Direito pela UNESP/Franca, professor de Direito Internacional e Teoria do Estado da Fafram/ FEItuverava, Direito Internacional e Direito Administrativo da Fadipa/UEMG-Passos, Teoria do Estado da UNIARA - Araraquara e Direito Internacional da LIBERTAS faculdades de São Sebastião do Paraíso 
A administração pública dá execução às decisões do governo.

\section{Estado e governo}

A diferença entre Estado e governo é atualmente mais acentuada com a personalização jurídica do Estado, porque o Estado como pessoa tem vontade própria, distinta da vontade individual do governante. No Estado Democrático e de Direito há a perspectiva de reduzir a participação do governo ao máximo possível. Fazem parte deste Estado e não fazem parte do seu governo a Constituição, o conjunto de servidores públicos estáveis, o patrimônio público, a máquina burocrática pública, as forças públicas, etc. Isto porque a sociedade precisa que estas instituições sejam estáveis e impessoais, que não estejam sujeitas às mudanças de governo no processo eleitorale que sejam republicanas - pertencente ao conjunto da sociedade e não aos interesses de quem está no poder. Isto é uma peculiaridade da democracia constitucional, nos regimes autoritários a ausência de limites aos governos os levam absorver ao máximo o Estado. O princípio republicano de responsabilidade política dos governos está presente nas constituições modernas das democracias e das monarquias, como limite ao poder e como identificação da coisa pública distinta do governo.

A personalização jurídica do Estadoé a sua identificação como pessoa, com vontade própria, caracterizada nos princípios de sua constituição. Um governo de um Estado que se legitima pelos princípios desse Estado terá uma margem de discricionariedade menor, sempre dentro destes princípios. Excepcionalmente e geralmente em momentos de crise, os governos buscam legitimação no carisma de seus líderes e de seus programas, mas é a legalidade conferida na ordem pública estatal a principal fonte de legitimidade moderna. Também o processo eleitoral de composição dos governos, com a distinção entre situação e oposição legitimando-se reciprocamente, contribui para a separação entre o Estado e o governo e para a sua legitimação.

O governo antecede ao Estado, pois é toda forma de organização do poder para a orientação de uma sociedade. Ainda que ocupe parte da estrutura do poder executivo, o governo é mais do que o executivo, pois se caracteriza por se estabilizar institucionalmente no Estado e assumir a responsabilidade da orientação política geral.

\section{As funções do estado e o governo}

As funções do Estado se confundem com os seus poderes, porque o Estado se legitima pela sua utilidade. Ao assumir um poder específico o associa a uma respectiva função social, ou seja, à idéia de que aquela capacidade é útil e necessária. Mas aqui não será identificado como poder, e sim por essa utilidade e necessidade.

OEstadoé um conjunto de órgãos responsáveis pelo desempenho de suas funções. Os órgãos do Estado fazem o que é do seu interesse, pois exercem o poder do Estado,

REVISTA UNIARA, $n .^{\circ} 21 / 22,2008 / 2009$ não possuem vontade própria, por isso são órgãos.

As funções são a executiva, a legislativae a judiciária. A função executivaé composta pela administração pública, como organização da burocracia estatal, e pelo governo, como conjunto de órgãos decisórios. O governo possuia discricionariedade, queéa liberdade de açãoe de escolha nos limites da legalidade, maso Estado possui princípios que limitam a opção ideológica dos governos. As opções ideológicas dos governos correspondem à fonte soberana do poder, que nas democraciasé expressa pelo votopopular, masédefinida por um conjunto complexo de forças sociais que compõe uma elite efetivamente poderosa. Porisso o executivo nãoé um mero executor das decisões legislativas.

A função legislativa é a essência do poder. É a fonte última das decisões e por isso se confunde com o poder soberano. Nas democracias que justificam o poder na vontade popular afirma-se que o legislador é o representante do povo. A prática tem demonstrado que o poder executivo é muito mais influente. O exercício do poder legislativo é geralmente atribuído a colegiados, para se obter uma maior distribuição da representatividade e para obter soluções mais discutidas e amadurecidas.

A função judiciária é de controle. Controle sobre os atos públicos e privados para a garantia da legalidade. Pela teoria de freios de contrapesos de Montesquieu, os atos judiciários são atos especiais como os atos do executivo. Eles estão na mesma categoria de identificação da lei com a realidade. Mas o judiciário não se limita à identificação da legalidade na sociedade, a produção de jurisprudência no preenchimento das lacunas da lei é uma verdadeira ação decisória.

No Estado de Direito as funções do Estado, caracterizadas na forma de poder, devem ser separadas para não caracterizar o benefício do poder para o indivíduo que a ocupa, segundo a teoria de freios e contrapesos. É neste sentido que as funções do Estado não devem também se confundir com os ocupantes do governo.

\section{A separação de poderes e as implicações no estado e no governo}

A Democracia Moderna, fundada no Estado de Direito e no constitucionalismo, se utiliza da Separação de Poderese da garantia dos Direitos fundamentais do homem. Junto com o seu presidencialismo, os EUA simbolizam o modelo de democracia que combina a separação de poderes em executivo, legislativo e judiciário com a responsabilidade política republicana de uma Constituição material, acima da vontade arbitrária dos governantes.

A separação formal dos poderes é uma característica de alguns Estados Democráticos e de Direito para a realização desta condição. De regra, os Estados antigos centralizaram as decisões das funções públicas. Em parte istoé decorrência do modelo de Estado Democrático e de Direito, mas em parte contribuiu o rol restrito de funções públicas, além de sociedades menores e menos burocratizadas. Para ocorrer a separação, a cada poder foi atribuído órgãos respectivos, com personalidade jurídica
Estado e governo: diferença conceitual... 
e independência, a ponto de muitas vezes se confundir o órgão com o poder. Entretanto a doutrina nos ensina que órgão público é um espaço dentro da administração, destinado a um fim. O órgão se caracteriza pela estrutura de organização, com os seus critérios de preenchimento, funcionamento e execução da finalidade, combinados com esta finalidade. Entretanto um órgão pode ser substituído por outro diferentemente caracterizado, permanecendo a finalidade. A função legislativa é comumente desempenhada por colegiados em órgãos como Assembléias, Câmaras, Congressos, Parlamentos, etc., a função executiva é comumente desempenhada por órgãos como presidências, gabinetes, prefeituras, etc. e a função judiciária possui órgãos como tribunais, varas, fórum, etc. Em alguns Estados a Separação de Poderes é ainda maior, com órgãos com um grau de autonomia em relação aos demais a ponto de politicamente serem reconhecidos como um novo poder. É o que ocorre com o Ministério Público no Brasil, ainda que a Constituição não indique assim expressamente.

Assim, a Separação de Poderes não é apenas a divisão de funções, ainda que esta pareça lógica e eficiente. É, na verdade, um mecanismo de autocontrole do Estado, com independência e atribuição de fiscalização recíproca entre os poderes. É inspirada na Teoria de Freios e Contrapesos de Montesquieu, segundo o qual os atos do Estado podem ser divididos em atos gerais e atos especiais. Os primeiros se caracterizam por serem indistintos, impessoais, e destinam-se a estabelecer regras gerais para a sociedade, é a ação de legislar, e os segundos se caracterizam por serem concretos, individualizados, e identificam os atos gerais com o comportamento das pessoas em sociedade, é a ação executiva. Para ocorrer a separação de poderes, que garante o autocontrole do Estado, é imperioso que os responsáveis pelos atos gerais não tenham controle e conhecimento sobre os destinatários destes atos, bem como os responsáveis sobre os atos especiais não tenham participação exclusiva na elaboração dos atos gerais e sejam apenas aplicadores da lei. Este mecanismo garante hipoteticamente que o indivíduo responsável pelo ato público não se beneficie individualmente da sua atribuição pública.

\section{Conclusões - a separação de poderes e a pós-modernidade}

Este modelo que garante a democracia e o Estado de Direito com a imposição de uma separação de poderes é aplicável e própria da modernidade. Na pós-modernidade o Estado perde a sua capacidade de articulação das funções, que estão engessadas, burocratizadas e sobrecarregadas. Gradativamente os Estados que adotaram a separação de poderes estão criando normas que implicam na ingerência de um poder no outro. Ea razão é muito simples: na pós-modernidade o fundamento moderno de legitimidade produzido por legalidade é substituído pelo fundamento da eficiência produzida pela operatividade. Aatual crise do Estado afeta indistintamente todas as suas instituições. As funções do Estado continuam as mesmas, até mesmo o pragmatismo de sua separação é aceito, entretanto no limite de sua eficiência, e não na necessidade de garantir um Estado Democrático e de Direito. Ademocraciae o Estado de Direito, por conseqüência também estão afetados, não somente pela inviabilidade da absoluta separação de poderes, mas porque a pós-modernidade está produzindo outros parâmetros para a política. Quando o indivíduo abandona o sentido de cidadania como uma ação para a realização de interesses públicos comuns e o substitui por uma cidadania de açãopública de realização de interesses privados a democracia tal qual como foi idealizada para a modernidade já não faz mais sentido. Isto atinge todas as suas instituições, não somente a separação de poderes, mas também tudo que implica na relação entre Estado e governo. O governo será muito mais um gestor das tensões produzidas pelo individualismo e a serviço de um ideal de eficiência tipicamente privado, do que uma equipe promotora dos ideais ideológicos de um grupo, segmento ou classe social.

\section{Referências bibliográficas:}

BOBBIO, Norberto. O futuro da democracia. São Paulo: Paz e Terra, 2004.

DUPAS, Gilberto. Tensões contemporâneas entre o público e o privado. Rio de Janeiro: Paz e Terra, 2003.

FARIA, José Eduardo (Org.). Direito e globalização econômica. Implicações e perspectivas. São Paulo: Malheiros Editores, 1996.

FERREIRAFILHO, Manoel Gonçalves. A democracia possível. São Paulo: Saraiva, 1978.

FREITAG, Michel. L'oubli de la sociéte: pour une théorie critique de la postmodernité. Rennes: Presses Universitaires de Rennes, 2002.

LASSALLE, Ferdinand. O que é uma Constituição? Leme: JGEditor, 2003.

OHMAE, Kenichi. O fimm do Estado-Nação. Rio de Janeiro: Campus, 1996.

PALLIERI, Giorgio Balladore. A doutrina do Estado. Coimbra: Coimbra Editora, 1969.

PAOLLI, M.C.; OLIVEIRA, F. Os sentidos da democracia. Petrópolis: Vozes, 1999. 
PIOVESAN, Flávia. Direitos humanos e direito constitucional internacional. São Paulo: Max Limoad, 1997.

ROCHA, Manoel Ilson Cordeiro. Reflexão sobre o conceito de soberania frente à desterritorialização provocada pela globalização econômica. 2000 . Dissertação (Mestrado) - UNESP, Franca, 2000.

ROUSSEAU, Jean-Jacques. O Contrato Social e outros escritos. São Paulo: Cultrix, 1980.

SANTOS, Boaventura de Souza. Pela mão deAlice: O social e o político na pósmodernidade. São Paulo: Cortez, 1995.

SILVA, José Afonso da. Curso de Direito Constitucional Positivo. São Paulo: Malheiros, 2006

WEBER, Max. Ciência e política, duas vocações. São Paulo: Cultrix, 1970.

Title:

STATE AND GOVERNMENT: CONCEPTUAL DIFFERENCE AND PRACTICAL IMPLICATIONS IN POSTMODERNITY

\section{Abstract:}

It is common and unjust to mix up State with government. The State is the whole political society, including government. The Government is mainly identified by the political group that is in the command of a State. The State has the executive, legislative and judicial functions. The government, in its executive function, is busy with managing the social and economical interests of the society, and in accordance with its ideological direction, establishes bigger or smaller levels of intervention. So, government should not be mixed up with executive power, which is composed by the government responsible for the political direction of the State, and by the administration, as a technical and bureaucratic group that helps the government and makes the public machine work. The public administration carries out the government decisions. In postmodernity the functions of the State are still the same, and even the pragmatism of its separation is accepted, however, considering its efficiency and not the necessity of guaranteeing a Democratic State of Right.

Keywords: Stat, Government, PostModernity. 